\title{
Prenatal Acetaminophen Affects Maternal Immune and Endocrine Adaptation to Pregnancy, Induces Placental Damage, and Impairs Fetal Development in Mice
}

\author{
Kristin Thiele, ${ }^{*}$ M. Emilia Solano, ${ }^{*}$ Samuel Huber, ${ }^{\dagger}$ Richard A. Flavell,, Timo Kessler, $^{\S}$ Roja Barikbin, ${ }^{\S}$ Roman Jung, ${ }^{\natural}$ \\ Khalil Karimi, ${ }^{\S}$ Gisa Tiegs, ${ }^{\S}$ and Petra C. Arck*
}

\begin{abstract}
From the Department of Obstetrics and Fetal Medicine, ${ }^{*}$ Laboratory of Experimental Feto-Maternal Medicine, the I. Department of Internal Medicine, ${ }^{\dagger}$ the Institute of Experimental Immunology and Hepatology, ${ }^{\S}$ and the Center for Diagnostics, ${ }^{\Uparrow}$ Department of Clinical Chemistry/Central Laboratories, University Medical Center Hamburg-Eppendorf, Hamburg, Germany; and the Howard Hughes Medical Institute, ${ }^{\ddagger}$ Yale University School of Medicine, New Haven, Connecticut
\end{abstract}

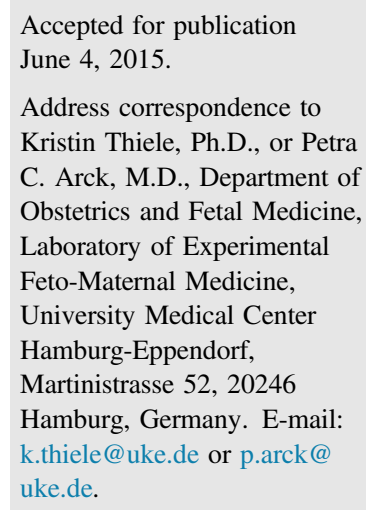

\begin{abstract}
Acetaminophen (APAP; ie, Paracetamol or Tylenol) is generally self-medicated to treat fever or pain and recommended to pregnant women by their physicians. Recent epidemiological studies reveal an association between prenatal APAP use and an increased risk for asthma. Our aim was to identify the effects of APAP in pregnancy using a mouse model. Allogeneically mated $\mathrm{C} 57 \mathrm{Bl} / 6 \mathrm{~J}$ females were injected i.p. with 50 or $250 \mathrm{mg} / \mathrm{kg} \mathrm{APAP}$ or phosphate-buffered saline on gestation day 12.5; nonpregnant females served as controls. Tissue samples were obtained 1 or 4 days after injection. APAP-induced liver toxicity was mirrored by significantly increased plasma alanine aminotransferase levels. In uterus-draining lymph nodes of pregnant dams, the frequencies of mature dendritic cells and regulatory $T$ cells significantly increased on $250 \mathrm{mg} / \mathrm{kg}$ APAP. Plasma progesterone levels significantly decreased in dams injected with APAP, accompanied by a morphologically altered placenta. Although overall litter sizes and number of fetal loss remained unaltered, a reduced fetal weight and a lower frequency of hematopoietic stem cells in the fetal liver were observed on APAP treatment. Our data provide strong evidence that prenatal APAP interferes with maternal immune and endocrine adaptation to pregnancy, affects placental function, and impairs fetal maturation and immune development. The latter may have long-lasting consequences on children's immunity and account for the increased risk for asthma observed in humans. (Am J Pathol 2015, 185: 2805-2818; http://dx.doi.org/10.1016/j.ajpath.2015.06.019)
\end{abstract}

Pregnancy maintenance and fetal development are highly vulnerable to challenges, including psychological stress, infections, and metabolic stress. ${ }^{1-3}$ The latter may be caused by the use of medication, such as acetaminophen (APAP; ie, Paracetamol and Tylenol).

APAP is an over-the-counter medication to treat fever and pain. In general, APAP is well tolerated when used in the therapeutic range., ${ }^{4,5}$ However, APAP can cause hepatotoxicity and accounts for almost $50 \%$ of all cases of acute liver failure in the United States, associated with a $30 \%$ mortality rate. $^{6}$ Moreover, APAP-induced hepatotoxicity can be mimicked in experimental models. ${ }^{7-9}$
Although the use of medication is generally avoided during pregnancy, APAP is one of the few drugs frequently taken by pregnant woman, ${ }^{10}$ because it is generally considered to be safe. Moreover, the Food and Drug Administration of the United States has classified APAP

\footnotetext{
Supported by grants from the German Research Foundation (TI169/11-1) and the Foundation for Research and Science Hamburg (10044) (G.T. and P.C.A.). K.T. received a fellowship from the University Medical Center Hamburg-Eppendorf.

G.T. and P.C.A. contributed equally to this work as senior authors.

Disclosures: None declared.
} 
into Pregnancy Category B, supporting that APAP can be used without concerns for maternal health and fetal development. ${ }^{11}$ However, there have been several clinical trials revealing a potential threat of APAP to pregnancy, because the occurrences of miscarriages, preterm birth, and low birth weight could be linked to APAP use. ${ }^{3}$ Moreover, several epidemiological studies have now provided unambiguous evidence that the prenatal use of APAP is associated with poor health in children later in life, such as an increased risk for the children to develop asthma. ${ }^{12,13}$

Because APAP is commonly self-medicated, a thorough documentation of the frequency and dosage of APAP medication used by pregnant women is largely unknown, along with the potential effect on maternal and fetal tissues. In rare cases, pregnancy complications have been associated with suicidal or unintentional overdose of APAP. ${ }^{3}$ The latter can result from misleading labels of medication remedies that include APAP.

Pregnancy maintenance results from the fine-tuned endocrine and immune adaptation of the mother to the semiallogeneic fetus, which promotes immune tolerance toward fetal antigens and thereby promotes fetal development. ${ }^{1}$ Key pathways of this maternal adaptation to pregnancy in mammals include the increased secretion of steroid hormones, such as progesterone, ${ }^{1}$ the arrest of dendritic cells (DCs) in a tolerogenic state, ${ }^{14-16}$ an increase of CD4 regulatory $\mathrm{T}$ (Treg) cells, ${ }^{17,18}$ and the occurrence of CD8 $\mathrm{T}$ cells with a regulatory phenotype. ${ }^{19-22}$ To date, insights on whether APAP affects such key pathways of maternal adaptation to pregnancy are still largely unknown.

Moreover, APAP freely crosses the placenta, which renders the fetus to be unprotected for a potential APAPinduced damage (eg, of the liver). ${ }^{23,24}$ Damage to the liver may pose an even increased threat for the fetus, because the fetal liver is a major source of hematopoietic stem cell (HSC) source in humans and in mice at distinct intervals of fetal development, ${ }^{25,26}$ before the HSC pool relocates to the bone marrow around birth. ${ }^{26}$ Liver-derived HSC-progenitor cells seed into the fetal thymus to undergo T-cell maturation. ${ }^{26}$ Hence, challenges to the fetal HSC pool in the liver (ie, in response to APAP) may result in an impaired fetal immune development. This, in turn, may have long-term consequences for children's immunity and health and provide a rationalization for the poor children's immunity observed on prenatal use of APAP. ${ }^{12,13}$ To date, insights on if and how the prenatal use of APAP may mediate such consequences are still unknown.

A comprehensive evaluation of the APAP-induced effects during pregnancy is largely missing. Therefore, we evaluated the effects of a nontoxic and a toxic single APAP dose on the maternal liver, as well as maternal immune and endocrine adaptation to pregnancy. We performed these analyses in mice, because this experimental approach has been proved to provide valuable insights relevant for human pregnancies. ${ }^{1,27,28}$ Moreover, we tested how prenatal APAP affects pregnancy outcome and alters fetal immune development in liver and thymus.

\section{Materials and Methods}

\section{Timed Pregnancies}

C57B1/6J female wild-type mice (aged 6 to 8 weeks), purchased from Charles River (Sulzfeld, Germany), and double knock-in FoxP3-IRES-mRFP (FIR)/IL-10 IRES green fluorescent protein-enhanced (Tiger) mice, abbreviated as the FIR/Tiger reporter mice, ${ }^{29,30}$ provided by R.A.F., were mated to CBy.SJL(B6)-Ptprc $\mathrm{a} / \mathrm{J}$ male mice. The presence of a vaginal plug in the morning was considered as gestation day (gd) 0.5. Maternal weight control on gd 8.5 and 10.5 was conducted to confirm pregnancy. Females of the same age were used as nonpregnant controls. Animals were kept under 12-hour light/dark circles and received food and water ad libitum. All experiments were performed in accordance with the animal ethics approval given by the State Authority of Hamburg (G11/094_APAP).

\section{APAP Treatment}

Sixteen hours before APAP treatment, pregnant and nonpregnant females were fasted to achieve equal glutathione levels. APAP was dissolved in sterile phosphatebuffered saline (PBS; Gibco by Life Technologies GmbH, Darmstadt, Germany), and pregnant (on gd 12.5) and nonpregnant mice were injected i.p. with 50 or $250 \mathrm{mg} / \mathrm{kg}$ APAP, respectively, in the morning. These APAP dosages match a dose of approximately $4 \mathrm{mg} / \mathrm{kg}$ (which is within the recommended single dosage) and $20 \mathrm{mg} / \mathrm{kg}$ (which is slightly higher than the recommended single dosage) in humans. These comparisons were obtained using the guidelines of the US Department of Health and Human Services, Food and Drug Administration, which facilitates conversion of human dosages to equivalent effects in mice (http://www.fda.gov/ downloads/Drugs/Guidance/UCM078932.pdf, last accessed May 20, 2015). The half-life of APAP in humans is well known and ranges between 2.0 and 3.0 hours, ${ }^{31}$ whereas it has been reported to vary between $>4$ and $<1$ hour in mice, dependent on the age. ${ }^{32}$ Control animals received PBS only. Pregnant mice were sacrificed either on gd 13.5 or 16.5 for harvesting maternal and fetal tissue; tissue from nonpregnant mice was obtained 24 or 96 hours after injection.

\section{Tissue Harvesting}

Mice were anesthetized lethally by i.v. injection of $150 \mathrm{mg} / \mathrm{kg}$ methohexital and $15 \mathrm{mg} / \mathrm{kg}$ heparin. Blood samples were collected by right ventricle cardiac puncture for assessments of plasma alanine aminotransferase (ALT) and progesterone levels. Maternal liver, spleen, and uterus-draining lymph nodes were harvested and kept in PBS on ice. Parts of the maternal liver were fixed in formalin for subsequent histology. The uterus was removed and kept in Hanks' balanced salt solution (HBSS; Gibco by Life Technologies GmbH), and number of implantations and abortions was documented to 
analyze pregnancy outcome in the respective pregnant mice. Fetuses were isolated from the embryonic membranes to determine fetal weight. Subsequently, the fetuses were stored in biopsy cassettes (Tissue-Tek III Blue; Sakura Finetek Europe, Alphen aan den Rijn, the Netherlands) on gd 13.5 and in embedding cassettes Macro (Carl Roth GmbH \& Co KG, Karlsruhe, Germany) on gd 16.5, incubated in Bouin's solution (Sigma-Aldrich, St. Louis, MO) for 24 hours, and then transferred into $70 \%$ ethanol. Fetal liver and thymus were harvested from four fetuses per litter on gd 16.5 using a S6E Stereo Zoom Microscope (Leica, Bensheim, Germany) and kept in RPMI 1640 medium (Gibco by Life Technologies $\mathrm{GmbH}$ ) containing $10 \%$ heat inactivated fetal bovine serum (HI FBS, Gibco by Life Technologies GmbH), $1 \%$ penicillinstreptomycin (Sigma-Aldrich), and 1\% L-glutamine (Gibco by Life Technologies $\mathrm{GmbH}$ ), called complete RPMI. Placentas taken on gd 13.5 and 16.5, respectively, were embedded in biopsy cassettes and stored in $4 \%$ formaldehyde solution (36.5\% to 38\%; Sigma-Aldrich) for 24 hours before transfer into $1 \%$ formaldehyde solution for long-term storage.

\section{Tissue Processing}

Single-cell suspensions of maternal lymph nodes were obtained by meshing the tissue through a cell strainer (Falcon Cell Strainer, $40 \mu \mathrm{m}$; BD Bioscience, Heidelberg, Germany). After centrifugation at $450 \times g$ for 8 minutes at $4^{\circ} \mathrm{C}$, the cell pellet was resuspended in fluorescence-activated cell sorter buffer $(1 \times$ PBS $+0.5 \%$ bovine serum albumin $)$.

The same cell isolation procedures were used for generating single-cell suspensions from fetal liver and maternal spleen, with the modification that red blood cell (RBC) lysis was performed using RBC lysis buffer (eBioscience, San Diego, CA) after centrifugation, according to the manufacturer's instruction. Single-cell suspensions from fetal thymus were obtained by processing the tissue in a scratched petri dish. Cell suspensions were then washed using a cell strainer with complete RPMI. After centrifugation, cells from fetal liver and thymus were resuspended in complete RPMI.

Single-cell suspensions from maternal liver were obtained by processing the tissue in a scratched petri dish. Cell suspensions were then washed with HBSS through a $100-\mu \mathrm{m}$ cell strainer. After centrifugation $(500 \times g, 5$ minutes, room temperature), the cell pellet was resuspended in $20-\mathrm{mL}$ Percoll-HBSS solution (60\% HBSS and $40 \%$ Percoll Working Solution [7.4-mL Percoll (GE Healthcare BioSciences AG, Uppsala, Sweden), $576 \mu \mathrm{L} 10 \times$ PBS, and $96 \mu \mathrm{L} \mathrm{7.5 \%} \mathrm{NaHCO}_{3}$ diluted in double-distilled water] and $100 \mathrm{U} / \mathrm{mL}$ heparin). Centrifugation was performed with low acceleration and no brake at $800 \times g$ for 20 minutes at room temperature. Finally, RBC lysis was performed using RBC lysis buffer, and the cells were resuspended in PBS.

A single-cell suspension from the uterus was obtained by enzymatic digestion [200 U/mL hyaluronidase (SigmaAldrich), $1 \mathrm{mg} / \mathrm{mL}$ collagenase VIII type (Sigma-Aldrich), and $1 \mathrm{mg} / \mathrm{mL}$ bovine serum albumin fraction V (Sigma-Aldrich)] dissolved in $5 \mathrm{~mL}$ HBSS. The uterus was incubated twice for 20 minutes in a $37^{\circ} \mathrm{C}$ water bath with agitation. Intermediately, the solution was recovered and filtered through a mesh, constantly washing with PBS. The solution was centrifuged at $450 \times g$ for 10 minutes at $4^{\circ} \mathrm{C}$ and resuspended in $6 \mathrm{~mL}$ PBS. The resuspended solution was pipetted on Lympholyte Cell Separation Media (Cedarlane Laboratories, Burlington, ON, Canada) and centrifuged immediately following the manufacturer's instructions.

The number of viable leukocytes in all tissues was obtained by counting the cells using a Neubauer chamber on adding Trypan Blue stain (0.4\%; Gibco by Life Technologies $\mathrm{GmbH})$.

\section{Histology of Maternal and Fetal Liver and Thymus}

For histological analysis, maternal livers were fixed in $4 \%$ formalin and fetuses were fixed with Bouin's solution before paraffin embedding. Sections were stained with hematoxylin and eosin following standard protocol and scanned with a Mirax Midi Slide Scanner (Zeiss, Oberkochen, Germany).

\section{Immunohistochemistry}

Fetuses were embedded in Tissue Tek (Sakura Finetek Europe) by use of liquid nitrogen and stored at $-80^{\circ} \mathrm{C}$ until histological sections were cut using the CryoStar NX70 (Thermo Scientific, Braunschweig, Germany). Subsequently, slides were dried and fixed in acetone for 10 minutes and finally stored at $-20^{\circ} \mathrm{C}$ after another 30 minutes of drying at room temperature. Immunohistochemical detection of keratin 14 and autoimmune regulator (AIRE) was performed as follows: Tissue was hydrated by incubation with tris-buffered saline (three times for 5 minutes) at room temperature. Sections were blocked with $2 \%$ goat serum diluted in Antibody Diluent (Dako, Hamburg, Germany) for 20 minutes. The primary antibodies keratin 14 (rabbit-anti-mouse, 1:2000) and AIRE (rat-anti-mouse, 1:200) were diluted in Dako Antibody Diluent, including 2\% HI FBS, and incubated overnight at $4{ }^{\circ} \mathrm{C}$. After washing, sections were incubated at room temperature for 1 hour in the dark, with the secondary antibodies (goat-anti-rabbit tetrarhodamine isothiocyanate, 1:200, and goat-anti-rat allophycocyanin, 1:100) diluted in Dako Antibody Diluent, including 2\% goat serum, 4\% mouse serum, and DAPI (1:20). Slides were covered with mounting media and stored at $4^{\circ} \mathrm{C}$ or $-20^{\circ} \mathrm{C}$ for short- and long-term storage, respectively. Image acquisition was performed using the Leica TCS SP5 confocal microscope.

\section{Histology of Placenta}

Placentas were embedded in paraffin and midsagittal sections (4 $\mu \mathrm{m}$ thick) were subsequently prepared using the Leica microtome SM2010R. Slides were dewaxed and rehydrated using xylene and ethanol. Masson-Goldner trichrome staining was performed following standard protocol. 
Subsequently, slides were also scanned with a Mirax Midi Slide Scanner. Histomorphological analyses of placental areas were performed by two independent observers (K.T. and T. Andreas) using a Pannoramic Viewer (3DHistech Kft, Budapest, Hungary).

\section{Flow Cytometry}

For flow cytometric analyses, $1.0 \times 10^{6}$ cells were used to stain maternal liver, spleen, blood, and uterus as well as fetal liver samples, and $0.5 \times 10^{6}$ fetal thymus or maternal lymph node cells, respectively, were used. Nonspecific binding was blocked by rat anti-mouse CD16/CD32 Mouse Fragment Crystallizable Block (1:200; BD Bioscience) and normal rat serum (1:100; eBioscience) for 15 minutes at $4^{\circ} \mathrm{C}$. Subsequently, the cells were incubated with the respective antibodies for 30 minutes for surface and intracellular staining. Antibodies used in this study are displayed in Table 1. In the protocol for surface staining, 7-amino-actinomycin D (1:400; Biolegend, Fell, Germany) was used to identify dead cells. For intracellular staining, cells were fixed and permeabilized using Foxp3 Fixation/Permeabilization Concentrate and Diluent (eBioscience). Data were acquired using a BD LSRFortessa II (BD Bioscience) and analyzed using FlowJo software version 9.8.1 (TreeStar, Ashland, OR).

\section{ALT and Progesterone Measurement}

Cardiac blood samples were centrifuged at $10,000 \times g$ for 20 minutes at $4^{\circ} \mathrm{C}$, and the supernatant plasma was immediately frozen at $-20^{\circ} \mathrm{C}$. ALT measurement was performed using COBAS INTEGRA 400 plus by Roche Diagnostics Ltd (Rotkreuz, Switzerland). For progesterone measurement, plasma samples were diluted 1:4 using the MultiDiluent 3 (Siemens Healthcare Diagnostic Ltd, Camberley, UK) and measured with a competitive immunoassay on the ADVIA Centaur XP Immunoassay System (Siemens Healthcare Diagnostic Ltd) using direct chemiluminescence, according to the manufacturer's instructions.

\section{RNA Isolation and cDNA Synthesis}

After tissue harvesting, a fraction of the maternal liver as well as fetal liver and thymus were preserved in RNAlater (Ambion by Life Technologies $\mathrm{GmbH}$ ) at $-20^{\circ} \mathrm{C}$. Tissue homogenization was performed using micropackaging vials with ceramic beads $(1.4 \mathrm{~mm})$ in a Precellys 24 Tissue

Table 1 Summary of Antibodies Used in the Present Study

\begin{tabular}{|c|c|c|c|c|}
\hline Target antigen & Fluorochrome & Clone & Dilution & Source \\
\hline Mouse lineage antibody cocktail & APC & & $1: 200$ & BD Bioscience (Heidelberg, Germany) \\
\hline Anti-Ly-6A/E (Sca-1) & PE-Cy7 & D7 & $1: 100$ & eBioscience (San Diego, CA) \\
\hline Anti-Ly-6G/Ly-6C (Gr-1) & BV 650 & $\mathrm{RB} 6-8 \mathrm{C} 5$ & $1: 200$ & Biolegend (Fell, Germany) \\
\hline MHC II & FITC & $14-4-4 S$ & $1: 100$ & BD Bioscience \\
\hline MHC II & APC & M5/114.15.2 & $1: 200$ & eBioscience \\
\hline Anti-FoxP3 & $\mathrm{PE}$ & FJK-16s & $1: 200$ & eBioscience \\
\hline Anti-CD1d & PerCP-Cy5.5 & 1B1 & $1: 200$ & BD Bioscience \\
\hline Anti-CD3 & PE-Cy7 & $145-2 C 11$ & $1: 200$ & Biolegend \\
\hline Anti-CD3 & APC-Cy7 & $145-2 C 11$ & $1: 200$ & Biolegend \\
\hline Anti-CD4 & FITC & RM4-5 & $1: 400$ & Biolegend \\
\hline Anti-CD4 & Pacific Blue & RM4-5 & $1: 400$ & Biolegend \\
\hline Anti-CD5 & APC & $53-7.3$ & $1: 200$ & BD Bioscience \\
\hline Anti-CD8 & PE-Су5 & $53-6.7$ & $1: 100$ & Biolegend \\
\hline Anti-CD8 & Pacific Blue & $53-6.7$ & $1: 100$ & Biolegend \\
\hline Anti-CD8 & BV650 & $53-6.7$ & $1: 100$ & Biolegend \\
\hline Anti-CD11b & BV785 & $\mathrm{M} 1 / 70$ & $1: 100$ & Biolegend \\
\hline Anti-CD11c & PE-Cy7 & N418 & $1: 100$ & Biolegend \\
\hline Anti-CD11c & BV711 & N418 & $1: 100$ & Biolegend \\
\hline Anti-CD19 & BV421 & $6 \mathrm{D} 5$ & $1: 100$ & Biolegend \\
\hline Anti-CD25 & APC & PC61 & $1: 200$ & Biolegend \\
\hline Anti-CD25 & BV605 & PC61 & $1: 200$ & Biolegend \\
\hline Anti-CD28 & APC & 37.51 & $1: 100$ & Biolegend \\
\hline Anti-CD34 & FITC & RAM34 & $1: 200$ & BD Bioscience \\
\hline Anti-CD44 & Pacific Blue & IM7 & $1: 200$ & Biolegend \\
\hline Anti-CD45 & APC-Cy7 & $30-F 11$ & $1: 400$ & BD Bioscience \\
\hline Anti-CD45R (B220) & AF700 & RA3-6B2 & $1: 100$ & eBioscience \\
\hline Anti-CD117 & BV 421 & $2 \mathrm{~B} 8$ & $1: 200$ & Biolegend \\
\hline Anti-CD122 & $\mathrm{PE}$ & TM-b1 & $1: 100$ & eBioscience \\
\hline Anti-CD135 & PE & $\mathrm{A} 2 \mathrm{~F} 10.1$ & $1: 100$ & BD Bioscience \\
\hline
\end{tabular}

APC, allophycocyanin; BV, brilliant violet; Cy, cyanine; FITC, fluorescein isothiocyanate; MHC, major histocompatibility complex; PE, phycoerythrin. 
Homogenizer (Peqlab, Erlangen, Germany). RNA isolation and DNA digestion were conducted by use of RNeasy Plus Universal Mini Kit (Qiagen, Hilden, Germany) and DNA-Free Kit (Applied Biosystems by Life Technologies $\mathrm{GmbH}$ ), respectively. cDNA synthesis was performed with random primers (Invitrogen by Life Technologies $\mathrm{GmbH}$ ). The concentration and purity of RNA and cDNA were assessed using NanoQuant (Tecan Group AG, Männedorf, Switzerland).

\section{Real-Time Quantitative RT-PCR}

Gene expression analyses of insulin-like growth factor 2 (IGF2) and AIRE were performed using gene expression assays (Igf2, Mm00439564_m1; AIRE, Mm00477461_m1) and the StepOnePlus Real-Time PCR System (Applied Biosystems by Life Technologies) and the corresponding software. Glyceraldehyde-3-phosphate dehydrogenase (Gapdh, Mm99999915_g1) and $\beta$-actin (Actb, Mm00607939_s1) served as endogenous controls to normalize cDNA content.

Gene expression analyses of collagen I (CollT1) and III (CollT3) and $\alpha$-smooth muscle actin ( $\alpha$-SMA) and ATP synthase $(A t p 5 b)$ as endogenous control were conducted by means of Absolute QPCR SYBR mix (Thermo Scientific by Life Technologies $\mathrm{GmbH}$ ) and the CFX96 real-time system (Biorad, München, Germany). Primer pairs used are listed in Table 2.

\section{Statistical Analysis}

All results are expressed as means \pm SEM. Means between groups were compared using one-way analysis of variance and Bonferroni's post tests using GraphPad Prism version 6.0 (GraphPad Software, La Jolla, CA).

\section{Results}

\section{APAP Induces Liver Toxicity in Pregnant and Nonpregnant Female Mice}

Plasma ALT and aspartate aminotransferase (AST) levels, indicators for liver damage, were significantly increased in pregnant animals on administration of $250 \mathrm{mg} / \mathrm{kg}$ APAP (Figure 1A). We observed an initial increase over the first 6 hours on injection, followed by a slight decrease at 12 hours. A second increase of ALT and AST followed 24 hours after APAP injection. Normalcy was reached 48 hours on APAP injection. The application of $50 \mathrm{mg} / \mathrm{kg}$ APAP did not result in increased ALT and AST levels in pregnant animals (data not shown). Histopathological evaluation of the liver revealed a centrilobular necrosis on administration of $250 \mathrm{mg} / \mathrm{kg}$ APAP to pregnant mice (Figure 1B), which was absent in the $50 \mathrm{mg} / \mathrm{kg}$ treated or control pregnant females. No significant differences were observed with regard to APAP-induced increased ALT levels and liver damage between nonpregnant and BALB/c-mated C57B1/6 females 24 hours on APAP injection (Supplemental Figure S1).

Moreover, a significantly increased maternal weight loss could be observed on injection of $250 \mathrm{mg} / \mathrm{kg}$ APAP within 24 hours and 4 days on injection of $50 \mathrm{mg} / \mathrm{kg}$ (Figure 1C). In additional analyses, we focused on the time point where APAP had the strongest effect ( 24 hours on injection) and assessed additional immune markers indicative for maternal liver damage. Herein, we could detect a significantly increased frequency of neutrophil granulocytes, identified as $\mathrm{CD} 3{ }^{\text {neg }} \mathrm{CD} 11 \mathrm{~b}^{+} \mathrm{Gr} 1^{+}$(Figure 1D), and a decreased frequency of $\mathrm{CD} 4^{+} \mathrm{FoxP}^{+}$Treg cells (Figure 1E) on injection of $250 \mathrm{mg} / \mathrm{kg}$ APAP.

Next, we assessed maternal livers for signs of fibrosis, on the basis of the mRNA expression of collagen I and III and $\alpha$-SMA ${ }^{33}$ and observed a significantly increased expression of collagen I and III in response to $250 \mathrm{mg} / \mathrm{kg}$ APAP (Figure 1, F and G), whereas expression of $\alpha$-SMA remained largely unaltered (Figure $1 \mathrm{H}$ ).

\section{APAP Affects Maternal Immune Adaptation to Pregnancy}

On gd 13.5 and 16.5 (both at 24 or 96 hours after APAP injection), the total number of cells, as well as $\mathrm{CD}^{+}$and $\mathrm{CD}^{+} \mathrm{T}$ cells harvested from the uterus-draining lymph nodes of pregnant mice, did not significantly differ on APAP challenges, although absolute cell numbers in lymph nodes from pregnant mice treated with $250 \mathrm{mg} / \mathrm{kg}$ APAP were lower compared with untreated, pregnant controls (Supplemental Figure S2, A-D).

Flow cytometric analyses of a distinct, pregnancyprotective CD8 subpopulation co-expressing CD122 in uterus-draining lymph nodes ${ }^{22}$ revealed no significant effect in response to both APAP dosages on 24 hours (on gd 13.5) (Figure 2A), but increased frequencies 96 hours on injection of $250 \mathrm{mg} / \mathrm{kg}$ APAP, on gd 16.5 (Supplemental Figure S2E). The frequency of DCs, defined as CD11c ${ }^{+}$, also remained unaffected on injection of both APAP dosages after 24 hours

Table 2 Primer Sequences for RT-PCR

\begin{tabular}{|c|c|c|c|}
\hline Target (gene) & Forward primer & Reverse primer & Sequence reference \\
\hline Mm ATP synthase $(A t p 5 b)$ & 5'-ATTGCCATCTTGGGTATGGA-3' & 5'-AATGGGTCCCACCATGTAGA-3' & NM_016774 \\
\hline Mm collagen, type I, $\alpha 1$ (Col1a1) & $5^{\prime}$-GAGCGGAGAGTACTGGATCG-3' & $5^{\prime}-\mathrm{TACTCGAACGGGAATCCATC-3^{ \prime }}$ & NM_007742 \\
\hline Mm collagen, type III, $\alpha 1$ (Col3a1) & $5^{\prime}-$ GTCCACGAGACAAAGGT-3' & $5^{\prime}$-GATGCCCACTTGTTCCATCT-3' & NM_009930 \\
\hline Mouse mRNA $\alpha$-SMA & 5'-GCATCCACGAAACCACCTAT-3' & $5^{\prime}-$ AGGTAGACAGCGAAGCCAAG- $3^{\prime}$ & X13297 \\
\hline
\end{tabular}

Mm, Mus musculus; $\alpha$-SMA, $\alpha$-smooth muscle actin. 


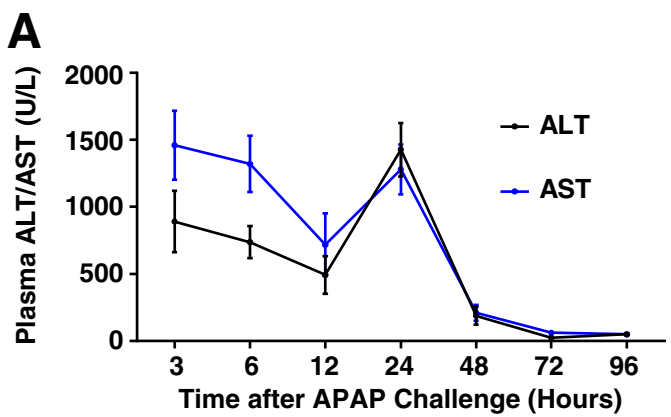

B
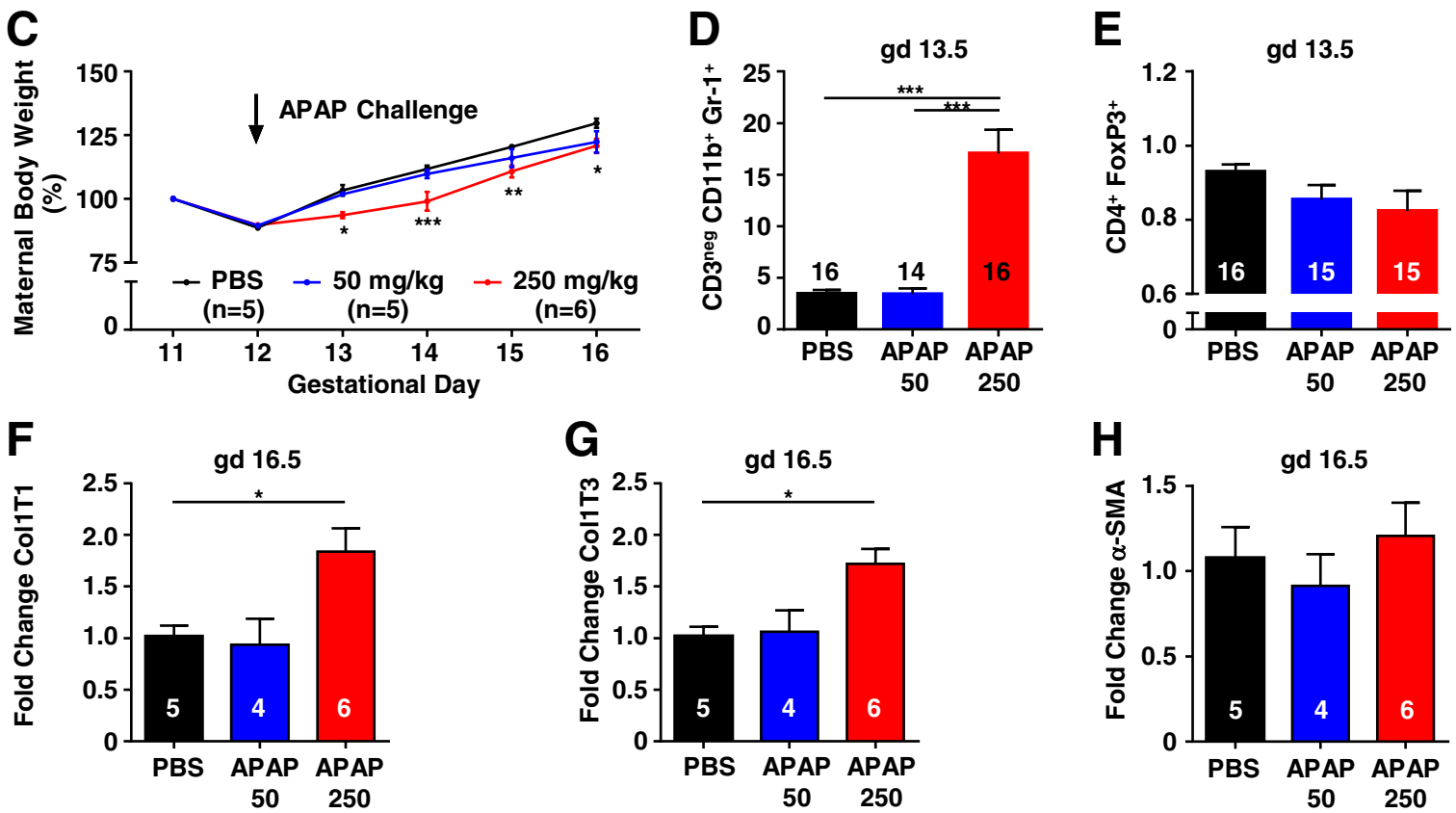

Figure 1 Acetaminophen (APAP) induces liver toxicity in pregnant mice. Pregnant mice were treated with either phosphate-buffered saline (PBS) or APAP ( 50 or $250 \mathrm{mg} / \mathrm{kg}$ ) on gestation day (gd) 12.5. A: Alanine aminotransferase (ALT; black) and aspartate aminotransferase (AST; blue) levels were analyzed at different time points after APAP challenge. Data are presented as time-dependent course. B: Representative images of paraffin tissue sections stained with hematoxylin and eosin display livers from pregnant mice treated with either PBS or APAP (50 or $250 \mathrm{mg} / \mathrm{kg}$ ). The arrow points to a necrotic area of centrilobular hepatocytes around a vein. C: Maternal body weight is presented over the course of pregnancy starting at the time of the food withdrawal until gd 16.5. D and E: Flow cytometry analysis of the maternal liver on gd 13.5. Frequencies are presented for neutrophil granulocytes (D) and regulatory T cells (E). $\mathbf{F}-\mathbf{H}$ : Gene expression analysis of maternal liver harvested on gd 16.5 to assess collagen I (F) and III (G) and $\boldsymbol{\alpha}$-smooth muscle actin ( $\alpha$-SMA; $\mathbf{H})$ expression; ATP synthase served as endogenous control. Data are presented as means $\pm \operatorname{SEM}(\mathbf{A}$ and $\mathbf{F}-\mathbf{H})$. ${ }^{*} P<0.05$, ${ }^{* *} P<0.01$, and ${ }^{* * *} P<0.001$.

(Figure 2B) and 96 hours (data not shown). However, the frequency of mature CD11 $\mathrm{c}^{+} \mathrm{DCs}$, defined as $\mathrm{CD} 11 \mathrm{c}^{+}$major histocompatibility complex class $\mathrm{II}^{+}$, was increased in lymph nodes of pregnant mice treated with $250 \mathrm{mg} / \mathrm{kg}$ APAP on 24 hours (Figure 2C and Supplemental Figure S2G), which was not present 96 hours on injection (data not shown).

The frequency of Treg cells in uterus-draining lymph nodes, defined as $\mathrm{CD}^{+}{ }^{+} \mathrm{FoxP}^{+}$, significantly increased 24 hours after injection in pregnant mice treated with $250 \mathrm{mg} / \mathrm{kg}$ APAP (Figure 2D and Supplemental Figure S2H). This increase was still present on gd 16.5 (Supplemental Figure S2F). We further investigated the functional role of these Tregs in more depth by taking advantage of the FIR/Tiger reporter mice, which allow the immediate and simultaneous detection of FoxP3 and IL-10 by flow cytometry without any experimental procedures to permeabilize the cell membrane. Injection of $250 \mathrm{mg} / \mathrm{kg}$
APAP into FIR/Tiger mice independently confirmed the increased frequency of $\mathrm{CD}^{+}{ }^{+} \mathrm{FoxP}^{+}$Tregs in uterusdraining lymph nodes observed in wild-type females on $\mathrm{gd}$ 13.5 (Figure 2E). Coincidentally, the frequency of IL-10-a strong marker for the suppressive function of Treg cells-was also increased in response to $250 \mathrm{mg} / \mathrm{kg}$ APAP (Figure 2F). We could also confirm similar APAP-induced liver damage in Fir/Tiger mice, mirrored by increased ALT and AST levels and neutrophil granulocyte influx into the liver, compared with wild-type mice (Supplemental Figure S3). We refrained from injecting FIR/Tiger mice with $50 \mathrm{mg} / \mathrm{kg}$ APAP, because no differences with regard to Treg frequencies could be observed in response to this dosage in wild-type mice. We could not observe any effect of $250 \mathrm{mg} / \mathrm{kg}$ APAP on the frequency of overall and IL-10-producing Treg cells in spleen (Figure 2, G and H) and in blood (data not shown). All reported cell subsets so far were additionally analyzed 
A
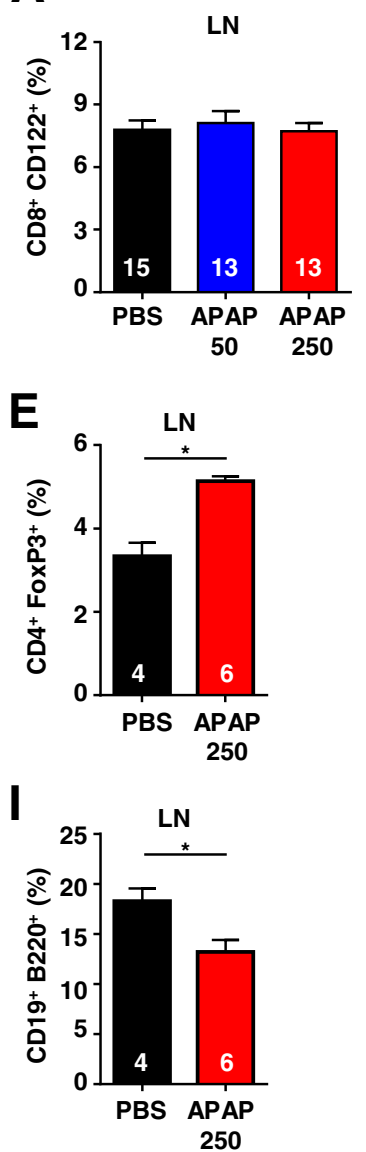

B
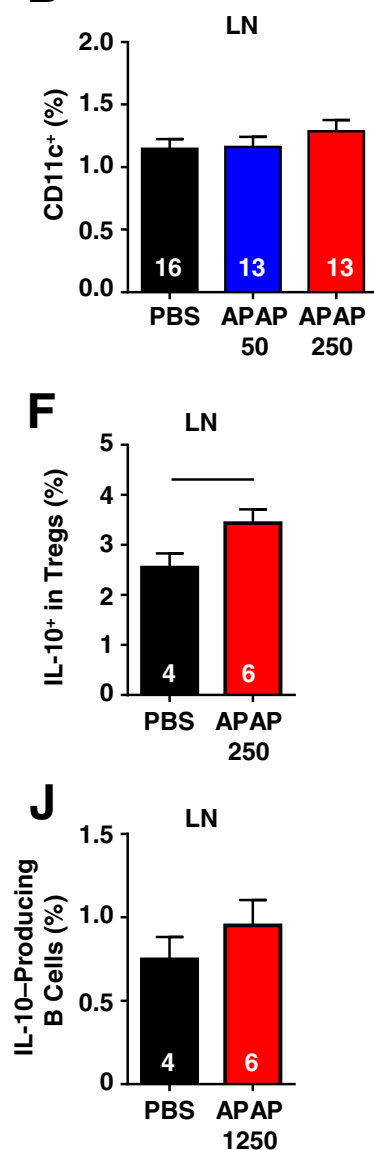

C
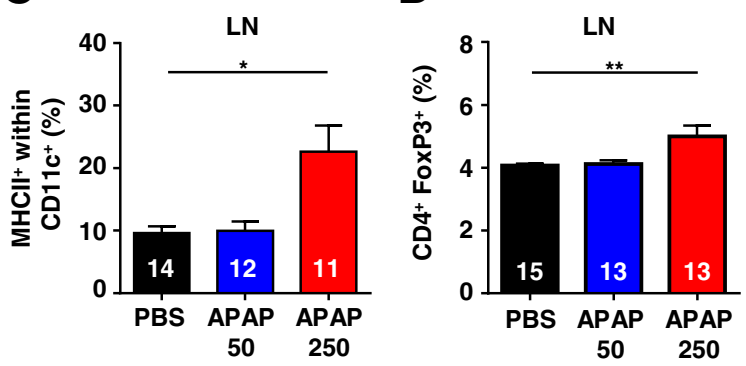

G
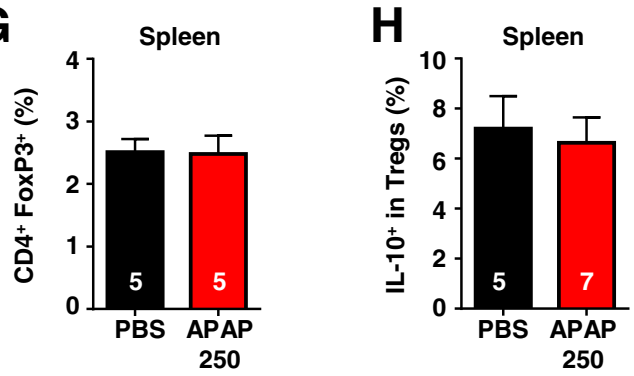

K
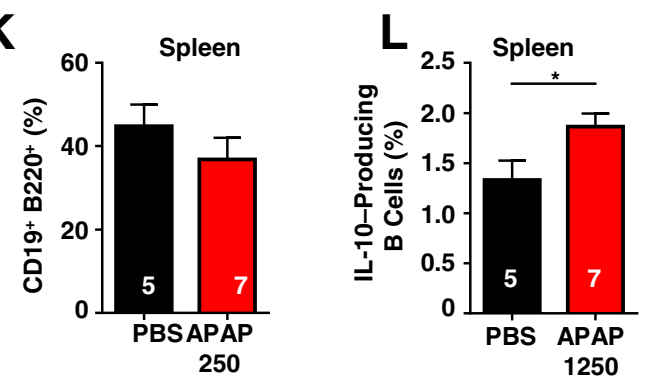

Figure 2 Acetaminophen (APAP) affects maternal immune adaptation to pregnancy. Pregnant mice were treated with either phosphate-buffered saline (PBS) or APAP ( 50 or $250 \mathrm{mg} / \mathrm{kg}$ ) on gestation day (gd) 12.5. Flow cytometry was performed on lymph node (LN) - and spleen-derived leukocytes 24 hours on APAP injection obtained from $\mathrm{C57Bl} / 6 \mathrm{~J}$ mice $(\mathbf{A}-\mathbf{D})$ or FoxP3-IRES-mRFP/Tiger mice $(\mathbf{E}-\mathbf{L})$, respectively. Graphs present the frequencies of regulatory CD8 ${ }^{+}$ $\mathrm{CD}_{122^{+}} \mathrm{T}(\mathbf{A})$ and $\mathrm{CD}_{11 \mathrm{C}^{+}}(\mathbf{B})$ cells. C: Frequencies of mature dendritic cells, defined as CD11c $\mathrm{c}^{+}$major histocompatibility complex (MHC) $\mathrm{II}^{+}$. D, E, and G: The frequencies of regulatory $\mathrm{CD}^{+} \mathrm{T}$ cells, defined as $\mathrm{CD}^{+}{ }^{+} \mathrm{FoxP}^{+} . \mathbf{F}$ and $\mathbf{H}$ : IL-10 production of regulatory T cells (Tregs). Graphs show the frequencies of $\mathrm{B}$ cells ( $\mathbf{I}$ and $\mathbf{K})$ and their expression of IL-10 ( $\mathbf{J}$ and $\mathbf{L})$. Data are presented as means \pm SEM. ${ }^{*} P<0.05,{ }^{*} P<0.01$.

in nonpregnant animals with the respective treatments, but no differences could be determined (Supplemental Figure $\mathrm{S} 2, \mathrm{I}-\mathrm{N})$.

A wealth of evidence is now available to support that B cells are capable of maintaining health and aggravating immune pathologies. ${ }^{34}$ Thus, we also focused on the effect of prenatal APAP on B-cell subsets using the FIR/Tiger mice. B cells, identified as $\mathrm{CD} 19^{+} \mathrm{B} 220^{+}$, were decreased in uterus-draining lymph nodes and spleen in response to injection of $250 \mathrm{mg} / \mathrm{kg}$ APAP (Figure 2, I and K), whereas the frequency of IL-10-producing B cells increased on APAP, and levels of significance were reached in spleen (Figure 2, $\mathrm{J}$ and $\mathrm{L}$ ).

\section{APAP Challenge during Pregnancy Impairs Placental Functional Areas and Reduces Maternal Progesterone Levels}

Histomorphological analysis of placental functional areas on gd 13.5 and 16.5 revealed that the overall placental surface area did not significantly differ between the groups on gd 13.5 and gd 16.5 (Supplemental Figure S4, A and B). When assessing the surface of the placental labyrinth and junctional zone, we observed a decreased labyrinth/junctional ratio on gd 13.5 in dams treated with $50 \mathrm{mg} / \mathrm{kg}$ APAP. Conversely, placentas from mice treated with $250 \mathrm{mg} / \mathrm{kg}$ APAP showed an increased labyrinth/junctional ratio, compared with gd 13.5 control placentas (Supplemental Figure S4, C and D). Evaluating the labyrinth/junctional ratio on gd 16.5, placentas from dams treated with either 50 or $250 \mathrm{mg} / \mathrm{kg}$ APAP showed a significantly increased ratio (Figure $3, \mathrm{~A}$ and D, and Supplemental Figure S4D). Alterations induced by $50 \mathrm{mg} / \mathrm{kg}$ APAP largely affected the junctional zone, because this area initially increased within 24 hours and subsequently significantly decreased on gd 16.5. Conversely, placental alterations induced by $250 \mathrm{mg} / \mathrm{kg}$ APAP resulted in an enlarged labyrinth at the expense of the junctional zone on both $\mathrm{gd}$ 13.5 and 16.5. Because the junctional zone represents a source of pregnancy-related hormones, we then determined the levels of progesterone in plasma and observed a 
A

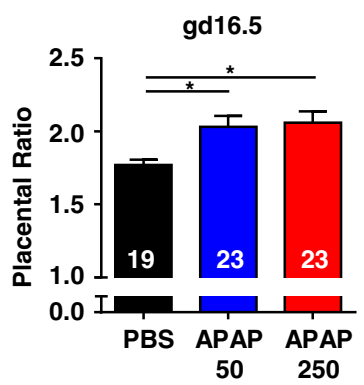

D

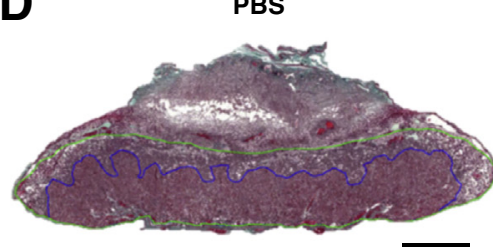

B
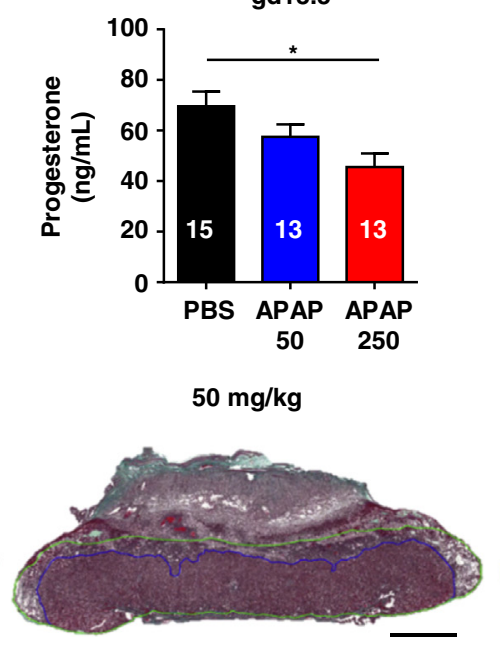

$\mathbf{E}$

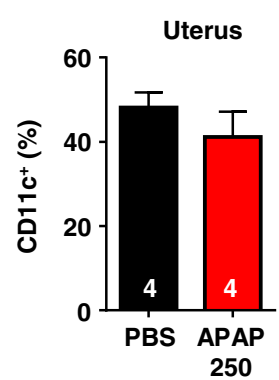

$\mathbf{F}$

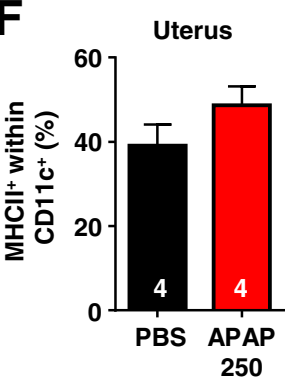

G

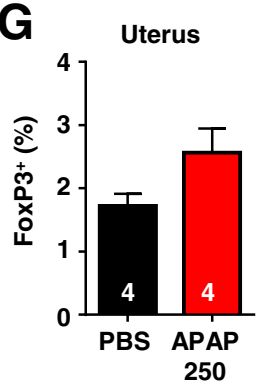

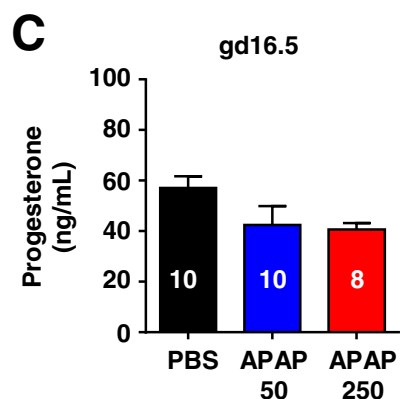
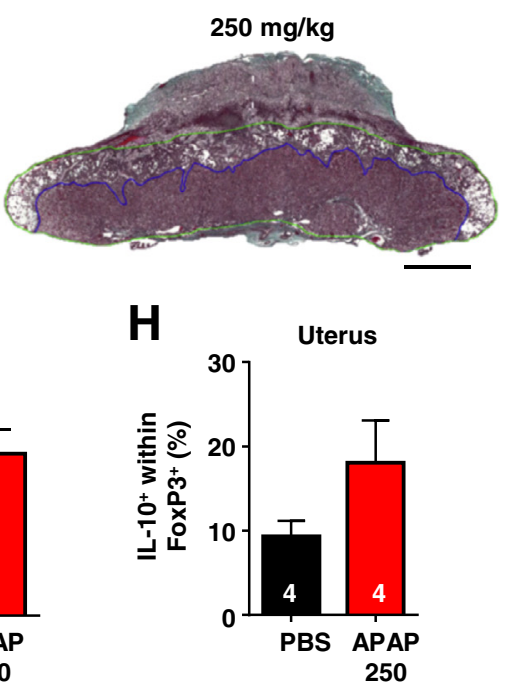

Figure 3 Acetaminophen (APAP) challenge during pregnancy affects placental functional areas and reduces maternal progesterone levels. Pregnant mice were treated with either phosphate-buffered saline (PBS) or APAP (50 or $250 \mathrm{mg} / \mathrm{kg}$ ) on gestation day (gd) 12.5, and placental histomorphology was performed. Placental ratios of labyrinth and junctional zone were calculated for $\mathrm{gd} 16.5$ (A), and representative images of placental transversal tissue sections are shown (D). Blue lines mark the labyrinth; and green lines, the entire labyrinth and junctional zone areas. Progesterone levels were determined on gd 13.5 (B) and gd 16.5 (C). E-H: Flow cytometry was performed on uterus-derived leukocytes 24 hours on APAP injection obtained from FoxP3-IRES-mRFP/Tiger mice. Frequencies are shown for $\mathrm{CD}_{11 \mathrm{c}^{+}}$cells $(\mathbf{E})$, mature dendritic cells $(\mathrm{DCS} ; \mathbf{F})$, Treg cells $(\mathbf{G})$, and their IL-10 production $(\mathbf{H})$. Data are presented as means $\pm \mathrm{SEM}$. ${ }^{*} P<0.05$. Scale bar $=1000 \mu \mathrm{m}$ (D). MHC, major histocompatibility complex.

dose-dependent decrease in response to APAP, compared with control animals, on gd 13.5 (Figure 3B) and gd 16.5 (Figure 3C). To test if the altered size of the junctional zone in the different groups is because of an altered rate of cell death, we assessed apoptosis by terminal deoxynucleotidyl transferase-mediated dUTP nick-end labeling as well as caspase 3 expression and observed a scarce positivity for terminal deoxynucleotidyl transferase-mediated dUTP nickend labeling in placenta and decidua basalis of PBS and APAP-treated mice (data not shown). Similarly, expression of caspase 3 could be detected in the decidua basalis, but differences between groups were not detectable (Supplemental Figure S4E), suggesting that the variance in size of the junctional zone is not because of an altered rate of cell death. Also, because the morphological assessments of placental specimens reveal the presence of leukocytes in the decidua, we further assessed frequencies of cell subsets in the decidua, which were modulated by prenatal APAP in uterusdraining lymph nodes, DCs, and Tregs, and observed no significant APAP-induced alterations of these subsets, although the frequencies of Tregs and IL-10 were observed to be increased (Figure 3, E-H).

\section{Prenatal APAP Application Impairs Fetal Development}

Next, we evaluated pregnancy outcomes and observed no significant differences with regard to the frequency of fetal loss and the total number of implantations in response to APAP, irrespective of the dose (Table 3). However, the fetal weight was dose dependently reduced 24 hours after

Table 3 Overview of Pregnancy Outcome on gd 13.5 and 16.5 at 24 and 96 Hours, Respectively, after Treatment with Either PBS or APAP

\begin{tabular}{lll}
\hline Pregnancy outcome & gd 13.5 & gd 16.5 \\
\hline $\begin{array}{ll}\text { Implantations } \\
\quad \text { PBS }\end{array}$ & $8.3 \pm 0.3(19)$ & $8.0 \pm 0.3(12)$ \\
$50 \mathrm{mg} / \mathrm{kg} \mathrm{APAP}$ & $7.7 \pm 0.3(17)$ & $8.6 \pm 0.3(11)$ \\
$250 \mathrm{mg} / \mathrm{kg} \mathrm{APAP}$ & $8.4 \pm 0.2(17)$ & $8.2 \pm 0.4(9)$ \\
Abortions (\%) & & \\
$\quad$ PBS & $7.4 \pm 2.1(19)$ & $3.1 \pm 1.6(12)$ \\
$50 \mathrm{mg} / \mathrm{kg} \mathrm{APAP}$ & $1.3 \pm 3.9(17)$ & $0.0 \pm 0.0(11)$ \\
$250 \mathrm{mg} / \mathrm{kg} \mathrm{APAP}$ & $4.6 \pm 1.7(17)$ & $2.8 \pm 1.9(9)$ \\
\hline
\end{tabular}

Data are given as means \pm SEM $(N)$.

APAP, acetaminophen; gd, gestation day; PBS, phosphate-buffered saline. 


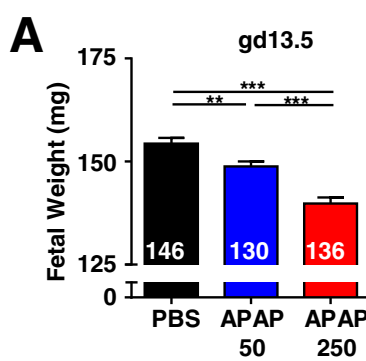

D

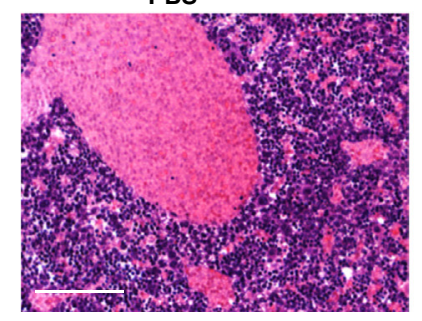

$\mathbf{E}$

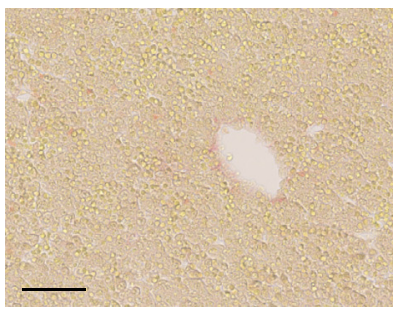

$\mathbf{F}$
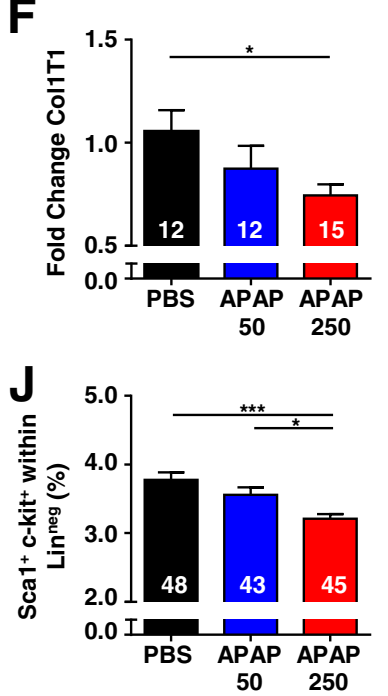
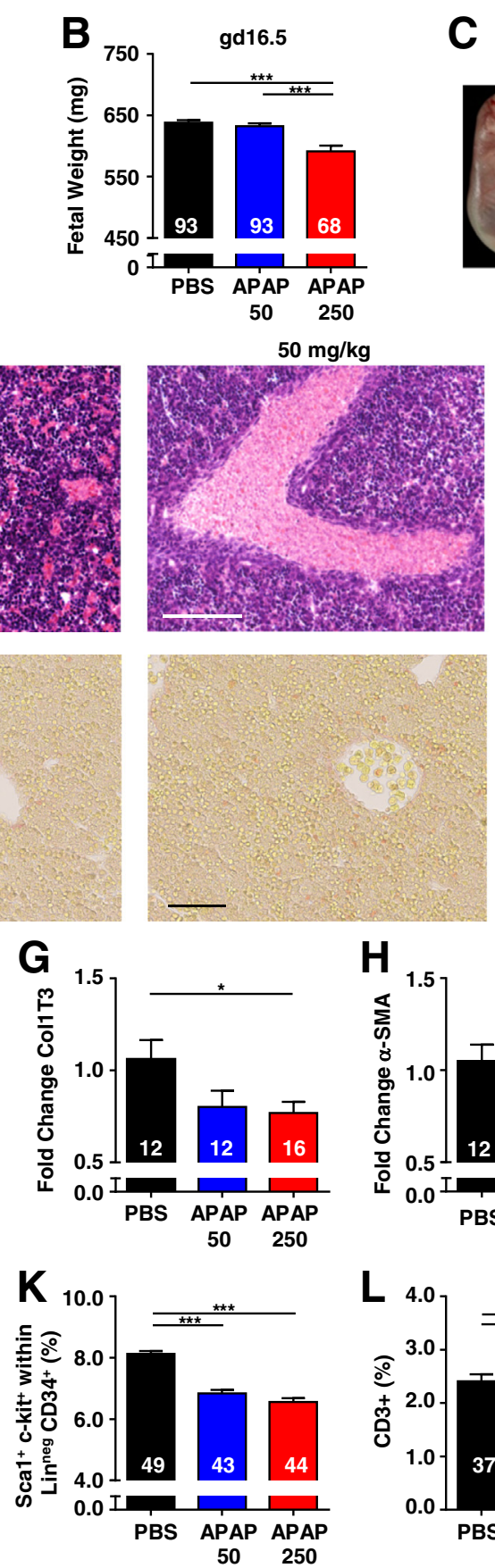
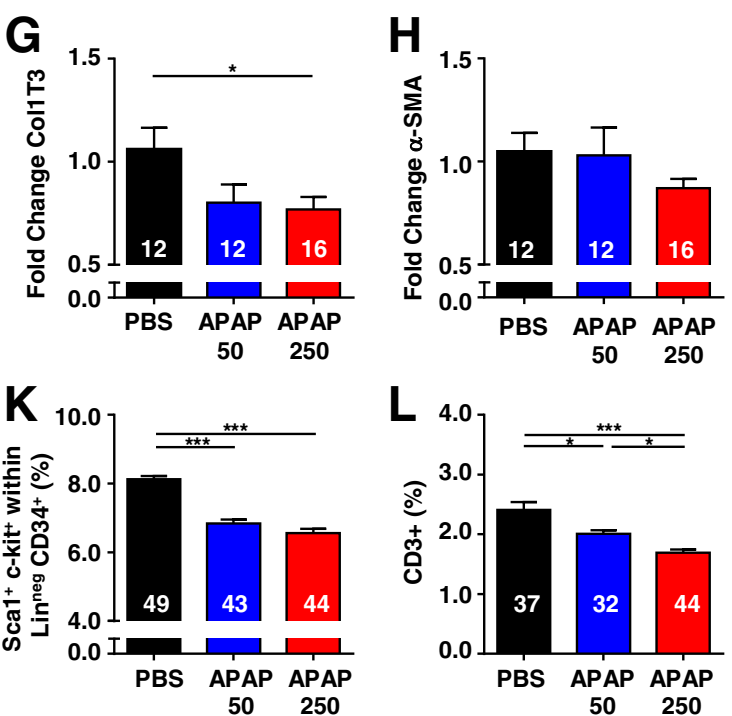
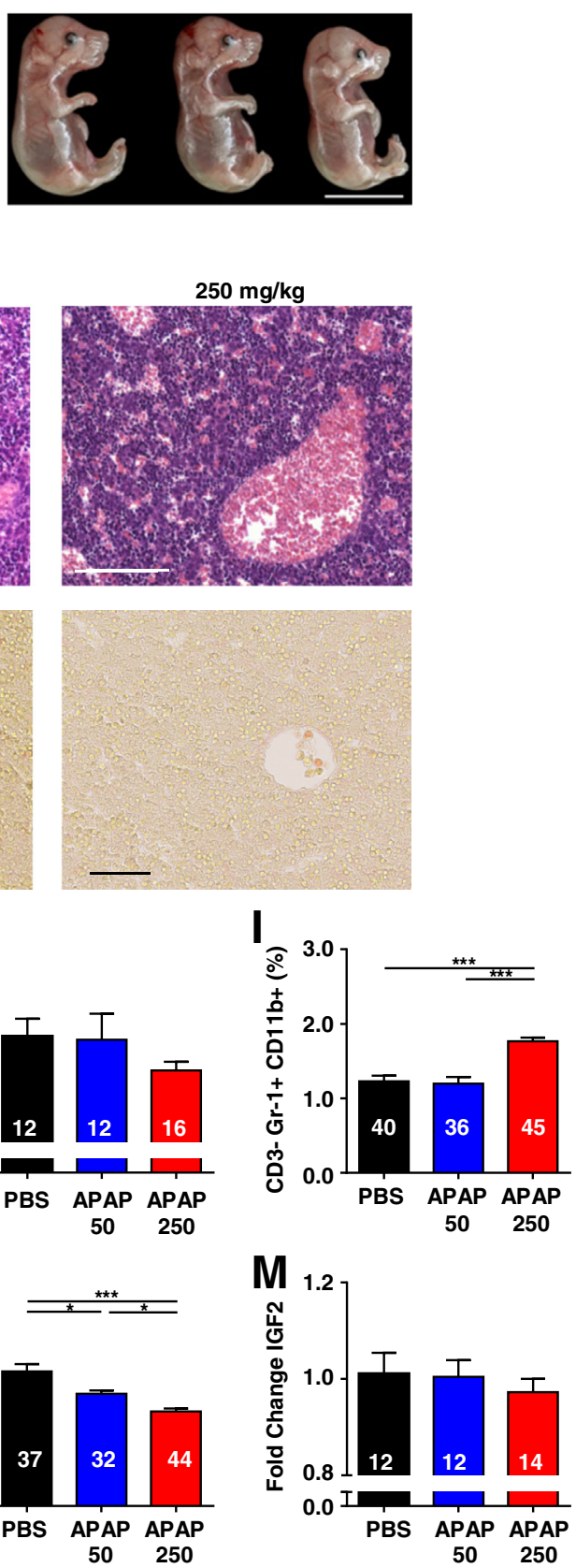

Figure 4 Prenatal acetaminophen (APAP) application impairs fetal development and hematopoietic stem cell (HSC) frequency in fetal liver. Pregnant mice were treated with either phosphate-buffered saline (PBS) or APAP $(50$ or $250 \mathrm{mg} / \mathrm{kg}$ ) on gestation day (gd) 12.5 , and fetal weight was calculated on gd 13.5 (A) and gd 16.5 (B). C: A representative image from fetuses of gd 16.5. D and E: Photomicrographs of hematoxylin and eosin (D) and Sirius Red (E) staining, performed on transverse sections in the lower thoracic region of fetuses from the respective treatment groups. I: Frequency of neutrophil granulocytes assessed by flow cytometry analysis of the fetal liver on gd 16.5. F-H: Gene expression analysis of fetal liver obtained on gd 16.5 to assess collagen I (F), III $(\mathbf{G})$, and $\alpha$-smooth muscle actin $(\alpha$-SMA; H) expression; ATP synthase served as an endogenous control. J-L: Frequencies of HSCs defined as $\mathrm{Lin}^{\text {neg }} \mathrm{CD} 117^{+} \mathrm{Sca}^{+}$cells $(\mathbf{J})$ and of multipotent progenitors defined as $\mathrm{Lin}^{\text {neg }} \mathrm{CD} 4^{+} \mathrm{CD} 117^{+} \mathrm{Sca} 1^{+}$cells $(\mathrm{K})$ were determined by flow cytometry in fetal liver cells harvested on gd 16.5. L: In addition, $\mathrm{CD}^{+}$cell frequency was assessed. M: Gene expression analysis of IGF2 in the fetal liver obtained on gd 16.5; $\beta$-actin served as an endogenous control. Data are presented as means \pm SEM. ${ }^{*} P<0.05,{ }^{*} P<0.01$, and ${ }^{* * *} P<0.001$. Scale bars: $10 \mathrm{~mm}(\mathbf{C}) ; 100 \mu \mathrm{m}(\mathbf{D}$ and E). IGF, insulin-like growth factor.

administration of APAP (Figure 4A). This fetal weight loss was still prominent 96 hours on injection of $250 \mathrm{mg} / \mathrm{kg}$ APAP, whereas 4 days after injection of $50 \mathrm{mg} / \mathrm{kg}$ APAP, fetal weight was restored to levels seen in controls
(Figure 4B). Representative examples of fetal size and development on gd 16.5 are shown in Figure 4C.

Then, we evaluated fetal liver morphology 4 days on APAP injection in transverse hematoxylin and eosin- and 
A

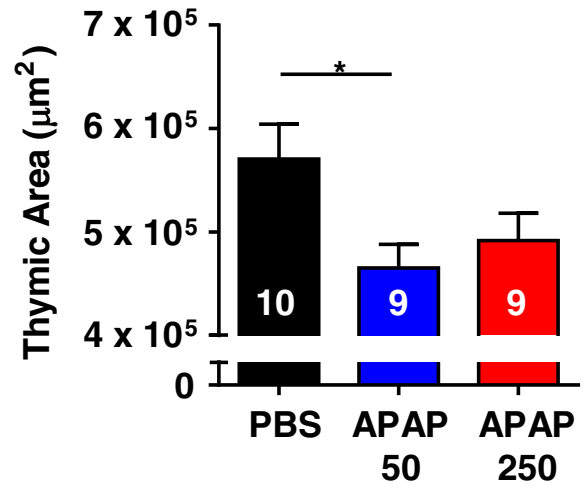

C

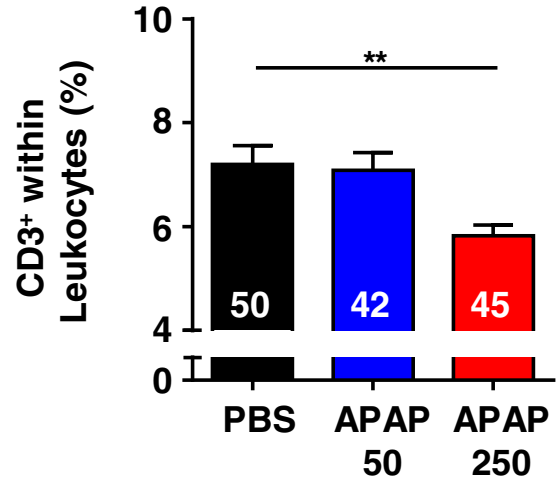

B
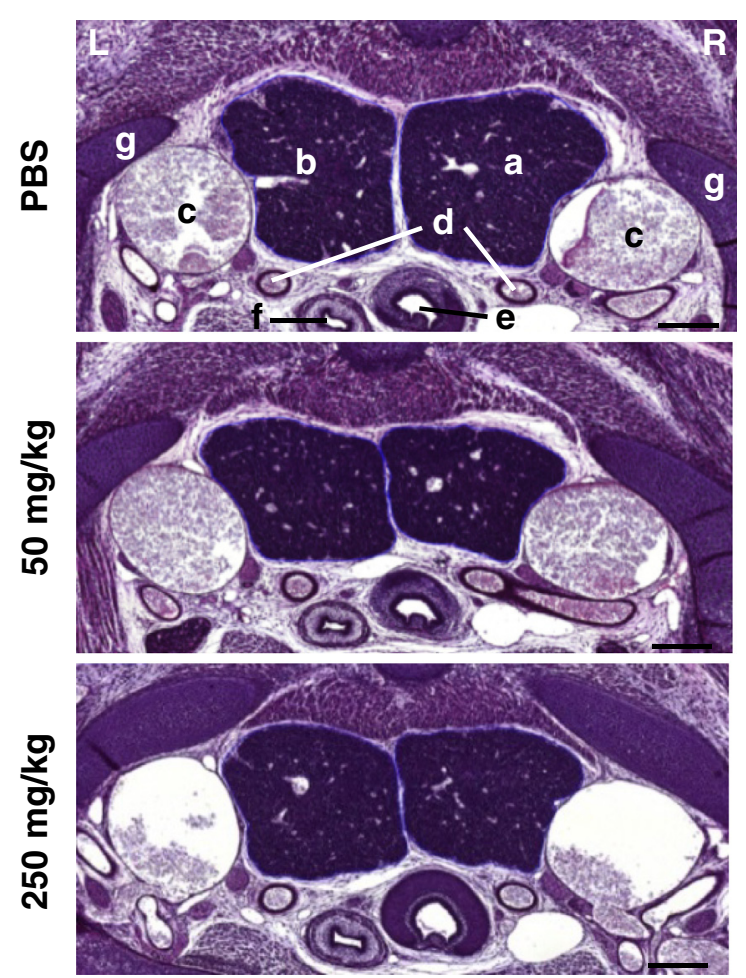

$\mathbf{E}$
D

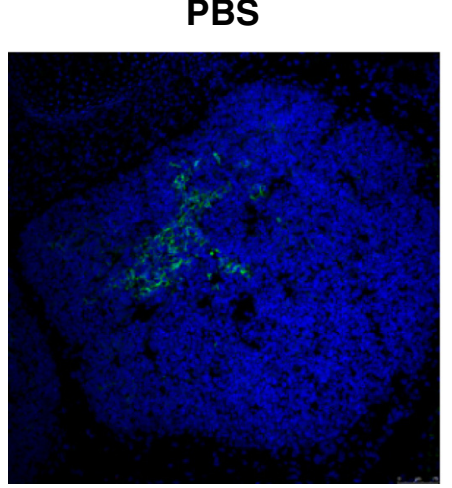

$250 \mathrm{mg} / \mathrm{kg}$

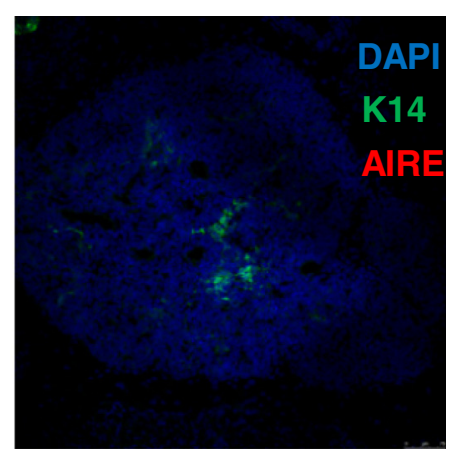

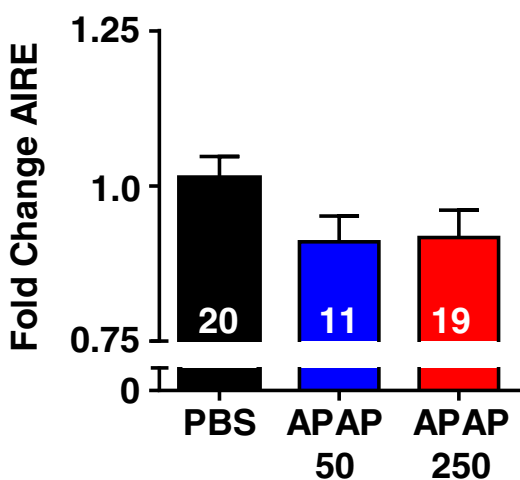

Figure 5 Prenatal acetaminophen (APAP) application impairs fetal T-cell development. Pregnant mice were treated with either phosphate-buffered saline (PBS) or APAP (50 or $250 \mathrm{mg} / \mathrm{kg}$ ) on gestation day (gd) 12.5. A: Transverse tissue sections in the upper thoracic region of fetuses from gd 16.5 were stained with hematoxylin and eosin, and the thymic area was calculated. B: Representative photomicrographs from fetuses exposed to PBS or APAP (50 and $250 \mathrm{mg} / \mathrm{kg}$ ). Morphological structures are described in the photomicrograph of a PBS-treated fetus. C: Fetal thymus was harvested on gd 16.5, and the frequencies of CD3 ${ }^{+}$ fetal thymic cells were analyzed by flow cytometry. D: Fluorescent immunohistochemistry for keratin 14 (K14; green), autoimmune regulator (AIRE; red), and DAPI (blue) performed on fetal thymic tissue obtained on gd 16.5. E: Gene expression analysis of AIRE in the fetal thymus obtained on gd 16.5; glyceraldehyde-3phosphate dehydrogenase served as an endogenous control. Data are presented as means \pm SEM. ${ }^{*} P<0.05, * * P<0.01$. a, right lobe of the thymus; $\mathrm{b}$, left lobe of the thymus; $c$, vena cava superior; $d$, carotid artery; e, trachea; $f$, esophagus; and $g$, cartilage primordium of the first rib; $L$, left; $R$, right.

Sirius red-stained histological tissue sections of the lower thoracic region. However, because of the dominant hematopoiesis, it was not possible to identify alterations of tissue architecture and signs for liver damage (Figure 4, D and E, and Supplemental Figure S5A). Therefore, similar to the analysis of maternal livers, we evaluated the mRNA expression of the fibrosis markers collagen I and III and $\alpha$-SMA in fetal liver and observed a decreased expression of all markers in response to $250 \mathrm{mg} / \mathrm{kg}$ APAP, which reached levels of significance for collagen I and III (Figure 4, F-H).

Thus, we assessed the phenotype of fetal liver cells by flow cytometry. We observe that the total number of cells isolated from fetal livers did not differ between groups (data not shown), but the frequency of neutrophil granulocytes was significantly increased, as also observed in dams (Figure 4I). Furthermore, fetal HSCs, defined as Lin ${ }^{\text {neg }}$, Sca$1^{+}{\mathrm{c}-\mathrm{Kit}^{+}}^{+}$(therefore also referred to as the LKS population), 
were significantly reduced in response to $250 \mathrm{mg} / \mathrm{kg}$ APAP injection (Figure 4J). Moreover, a decrease of hematopoietic progenitor cells, defined as $\mathrm{Lin}^{\text {neg }}, \mathrm{CD} 34^{+}, \mathrm{Sca}_{-} 1^{+}$, and

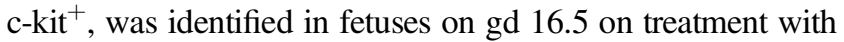
both APAP doses (Figure 4K and Supplemental Figure S5, B and $\mathrm{C}$ ). Because $\mathrm{CD}^{+}$cells in the fetal liver have been attributed to support the expansion of HSCs,${ }^{35}$ we assessed the frequency of $\mathrm{CD}^{+}$cells in the liver and observed a significant reduction in response to APAP treatments (Figure $4 \mathrm{~L}$ ). Because CD3-derived IGF2 is presumed to contribute to the HSC-supportive environment, we further assessed the expression of IGF2 in the overall fetal liver and could confirm a slightly decreased expression (Figure $4 \mathrm{M}$ ).

\section{Prenatal APAP Application Impairs Fetal T-Cell Development}

Liver-derived progenitor cells seed into the thymus, where they differentiate into $\mathrm{T}$ cells. Therefore, we then analyzed the fetal thymus and observed a decrease of the transversal area in gd 16.5 thymus histological tissue sections in response to APAP, which was surprisingly more profound on treatment with $50 \mathrm{mg} / \mathrm{kg}$ rather than $250 \mathrm{mg} / \mathrm{kg}$ APAP (Figure 5A). Representative photomicrographs of hematoxylin and eosin-stained sections of fetal thymuses are shown in Figure 5B. Conversely, we observed no difference in the number of cells isolated from the fetal thymus (data not shown). However, flow cytometry analysis revealed a decrease of $\mathrm{CD}^{+}$cells among cells double negative for CD44 and CD25 in fetuses exposed to $250 \mathrm{mg} / \mathrm{kg}$ APAP (Figure 5C and Supplemental Figure S6A). Furthermore, the co-expression of CD8 and/or CD4 was reduced in leukocytes isolated from the fetal thymus on APAP treatments (Supplemental Figure S6, B-D). Overall, these findings indicate a delay of T-cell development in response to APAP challenge. Because we observed a reduction of the overall fetal thymus size in the absence of a reduced number of cells isolated, we then evaluated if prenatal APAP affects other thymic populations. Herein, we focused on thymic epithelial cells, identified by their expression of the transcription factor AIRE. No AIRE protein expression could be detected in the fetal thymus by immunohistochemistry (Figure 5D), which is likely because of the early time point during fetal development at which we analyzed the fetuses. Therefore, we assessed AIRE expression on the mRNA level and observed a decrease on APAP injections (Figure 5E).

\section{Discussion}

We herein provide evidence that prenatal application of APAP in mice causes maternal liver damage and affects the immune and endocrine adaptation to pregnancy. Moreover, placental function, fetal development, and immune ontogeny were significantly impaired by prenatal APAP. Such investigations were motivated by the lack of insights on pathways involved in mediating the effects of prenatal APAP on the poor health of children later in life (eg, an increased risk for asthma). ${ }^{12,13}$

The APAP dosages we administered had been calculated on the basis of the body weight, which increases during pregnancy in mice. Hence, one might argue that pregnant mice received a higher dose of APAP, compared with the nonpregnant controls. However, the liver of pregnant mice is also increased in proportion to the body weight because of physiological changes to support fetal growth and development, which appears to equipoise the higher APAP dose. ${ }^{36}$ We used two different APAP doses, 50 or $250 \mathrm{mg} /$ $\mathrm{kg}$ body weight, which were both administered as single injections. The dose of $50 \mathrm{mg} / \mathrm{kg}$ APAP can be considered to be within the therapeutic range, hereby reflecting a medication frequently taken during pregnancy in humans. The second dose, $250 \mathrm{mg} / \mathrm{kg}$ APAP, is higher than the single dose limit recommended during pregnancy. However, such a high APAP dose is not uncommon because of the additive APAP intake occurring when using so-called drug cocktails (eg, to treat a common cold). ${ }^{37}$

Surprisingly, compared with nonpregnant mice, we did not observe a significantly increased susceptibility to liver damage/ALT levels on application of high-dose APAP in pregnant mice within the allogenic mating combination used. In contrast, an increased APAP-related hepatotoxicity has been described in syngenically pregnant Crl:CD-1 BR Swiss mice, mirrored by an increased serum ALT activity, higher incidence of liver necrosis, and greater mortality. ${ }^{36} \mathrm{In}$ our group, we also observed an enhanced APAP-induced hepatotoxicity in syngenically mated C57B1/6 females. ${ }^{38}$ Hence, one might argue that the maternal system may be able to better cope with liver inflammation in pregnancies that require an increased immunological adaptation because of the allogeneic fetus.

Moreover, liver metabolism might be altered in pregnant mammals. In humans, an increased half-life of APAP was described during pregnancy. ${ }^{39}$ Hence, an attenuated metabolism might result in higher steady-state levels of the toxic metabolite of APAP, $N$-acetyl-p-benzoquinone imine, ${ }^{40}$ which could be detoxified by glutathione before protein binding. However, future studies are needed to clarify this issue.

We further report that prenatal APAP reduced the pregnancy hormone progesterone, which could result from antiestrogenic responses to APAP, such as the inhibition of progesterone receptor up-regulation in the uterus, which was observed in immature female mice after APAP treatment. ${ }^{41}$ Although functional withdrawal of progesterone and reduced nuclear expression of the progesterone receptor subtypes on human decidual cells have been proposed to contribute to the initiation of preterm delivery, ${ }^{42}$ we did not observe preterm delivery on APAP treatment in mice.

APAP treatment can induce inflammation, ${ }^{43}$ and inflammation affects the ovaries by facilitating monocyte infiltration and interfering with ovarian steroidogenesis in mice. ${ }^{44}$ Hence, APAP may account for the decrease of progesterone 
we herein described via an increased monocyte inflammation into ovaries. Also, the altered size of the junctional zone we observed in response to prenatal APAP could also be indicative for a modulation of hormones triggering the release of ovarian progesterone during pregnancy in mice (ie, placental lactogen 2). Thus, we assessed the expression of placental lactogen 2 and observed a decrease in response to injection of $250 \mathrm{mg} / \mathrm{kg}$ APAP, whereas placental lactogen 2 expression was unaltered on $50 \mathrm{mg} / \mathrm{kg}$ APAP compared with controls, despite the increased size of the junctional zone on gd 13.5 (data not shown).

Progesterone promotes maternal immune adaptation to pregnancy by supporting the immature, tolerogenic phenotype of DCs. ${ }^{45}$ This is consistent with our findings, because we could show that APAP treatment induces an up-regulation of maturation marker, such as major histocompatibility complex class II. However, the causal link between the increased maturation of DCs and the poor fetal development observed in response to prenatal APAP remains to be proved in future studies.

Furthermore, APAP affected the adaptive arm of maternal immune adaptation to pregnancy, because frequencies of $\mathrm{CD} 4^{+}$Foxp $^{+}$Tregs were significantly increased in uterusdraining lymph nodes of dams treated with $250 \mathrm{mg} / \mathrm{kg}$ APAP. Tregs are critically involved in limiting several inflammatory responses ${ }^{46-48}$ and contribute to the acquisition and maintenance of tolerance during pregnancy. ${ }^{1,18}$ Although the conceptual relevance of these observations needs to be provided, one might speculate that the increase of Tregs in uterine-draining lymph nodes of APAP-treated dams could be a protective mechanism against immune response triggered by APAP administration, mounted to rescue pregnancy maintenance. Noteworthy, we observed only a marginal increase of Treg cells in uterus-draining lymph nodes with pregnancy, which may be explained by their rapid recruitment to the uterus.

Decreased levels of progesterone have been associated with a lower birth weight in humans, especially in female children. ${ }^{49}$ In the present study, we also observe a decreased fetal weight in response to APAP, whereby it remains to be elucidated if this reduced fetal weight is because of low levels of maternal progesterone, an impaired placental function, or a direct effect of APAP on the fetus. The latter possibility may result from the ability of APAP to cross the placental barrier. ${ }^{23}$

In the fetus, APAP may be metabolized by the fetal liver by conjugation with glutathione and sulfate, although detoxification by glutathione conjugation is reported to be decreased in the fetal liver. ${ }^{50}$ In the present study, APAP was injected on gd 12.5, concurrent with the translocation of hematopoiesis from the extraembryonic yolk sac and the intraembryonic para-aortic splanchnopleura/aorta-gonadmesonephros region to the fetal liver. ${ }^{51,52}$ Hence, the fetal liver may be particularly susceptible to hepatotoxicity, resulting in the decline of HSCs and hematopoietic progenitor cells we herein describe. HSCs produce erythrocytes, myeloid cells, and lymphocytes. Thus, an impaired HSC pool may affect the maturation of the lymphoid cell lineage and hereby interfere with the fetal immune ontogeny. Liverderived, T-cell progenitor cells seed the thymus in two waves and undergo a complex process of differentiation and selection to generate mature, self-major histocompatibility complex-restricted T cells. ${ }^{26}$ Hence, damage to the HSC pool in the liver may have consequences for the T-cell repertoire. Indeed, we observed a decreased frequency of $\mathrm{CD}^{+}$cells in the thymus, which suggests a delayed T-cell maturation or changes in the selection processes.

Our findings of an impaired immune ontogeny in response to prenatal APAP may now provide an explanation for the association between prenatal APAP use and immune diseases during childhood, such as allergic asthma. ${ }^{53}$ Clearly, future research aiming to confirm causality between the delayed fetal immune maturation and subsequent asthma risk is needed, as well as the identification or exclusion of an APAP-induced damage of the fetal lung.

Herein, we observed a considerable variability in the experimental outcomes on APAP administration, with regard to the fetal weight. However, fetuses in the group treated with $250 \mathrm{mg} / \mathrm{kg}$ APAP, which did not show a reduction in weight, also revealed a reduced frequency of HSCs. These data suggest that the fetal weight is not solely associated with the immune profile in APAP-treated animals. We also excluded that this variability was because of a sex-specific APAP response by assessing female and male fetuses separately (data not shown). Beyer et al ${ }^{54}$ proposed that genetic differences and epigenetic modifications may influence the susceptibility toward APAP, because they reported a considerable degree of animal-to-animal variability with regard to the extent of APAP-induced liver injury in C57B1/6J mice. Moreover, not only intrastrain variability with regard to APAP toxicity, but also strain-dependent variable degrees of liver damage, as assessed in 36 different mouse strains, have been reported. ${ }^{55}$ Hence, the allogenic mating combination used in this study may have influenced the impact and variability of APAP on mother and fetus. In humans, a variability of APAP-associated liver damage has also been described (eg, in individuals carrying the CYP3A5 rs776746 A). ${ }^{56}$ Moreover, individuals homozygous for the CD44 rs 1467558 A allele were observed to have elevated serum liver enzymes after consumption of high doses of APAP for up to 2 weeks. ${ }^{56}$ No data are available to indicate whether pregnancy aggravates APAPinduced liver damage in these patients.

Taken together, our data provide evidence that caution should be required when using APAP during pregnancy, because it induces placental damage and impairs fetal immune maturation in mice. Clearly, abstaining from APAP medication during pregnancy may also be associated with negative repercussions for the unborn child (eg, when maternal fever is not reduced). ${ }^{57}$ Insights from longitudinal pregnancy cohorts are urgently required, in which the use of APAP is thoroughly documented and linked to potential alterations of fetal immune maturation (eg, via assessments of HSC subsets and T-cell maturation in cord blood). 


\section{Acknowledgments}

We thank Agnes Wieczorek, Thomas Andreas, and Elena Tasika (University Medical Center Hamburg-Eppendorf (UKE), Hamburg, Germany) for their technical assistance; Dr. Alexander Quaas (UKE) for his support with regard to the histopathological evaluation of the maternal and fetal liver sections; Jörg Sägebarth for imaging support; and the UKE FACS Sorting Core Unit, the UKE Microscopy Imaging Facility, and the UKE Mauspathology for providing the equipment and technical support.

\section{Supplemental Data}

Supplemental material for this article can be found at http://dx.doi.org/10.1016/j.ajpath.2015.06.019.

\section{References}

1. Arck PC, Hecher K: Fetomaternal immune cross-talk and its consequences for maternal and offspring's health. Nat Med 2013, 99: $548-556$

2. Gabriel G, Arck PC: Sex, immunity and influenza. J Infect Dis 2014, 209:593-599

3. Thiele K, Kessler T, Arck P, Erhardt A, Tiegs G: Acetaminophen and pregnancy: short- and long-term consequences for mother and child. J Reprod Immunol 2013, 97:128-139

4. Geba G, Weaver A, Polis A, Dixon M, Schnitzer T: Efficacy of rofecoxib, celecoxib, and acetaminophen in osteoarthritis of the knee: a randomized trial. JAMA 2002, 287:64-71

5. Gelotte CK, Auiler JF, Lynch JM, Temple AR, Slattery JT: Disposition of acetaminophen at 4,6 , and $8 \mathrm{~g} /$ day for 3 days in healthy young adults. Clin Pharmacol Ther 2007, 81:840-848

6. Lee WM: Acetaminophen-related acute liver failure in the United States. Hepatol Res 2008, 38:3-8

7. Bhushan B, Walesky C, Manley M, Gallagher T, Borude P, Edwards G, Monga SPS, Apte U: Pro-regenerative signaling after acetaminophen-induced acute liver injury in mice identified using a novel incremental dose model. Am J Pathol 2014, 184:3013-3025

8. Scheiermann P, Bachmann M, Goren I, Zwissler B, Pfeilschifter J, Mühl H: Application of interleukin-22 mediates protection in experimental acetaminophen-induced acute liver injury. Am J Pathol 2013, 182:1107-1113

9. Sullivan BP, Kassel KM, Jone A, Flick MJ, Luyendyk JP: Fibrin (ogen)-independent role of plasminogen activators in acetaminopheninduced liver injury. Am J Pathol 2012, 180:2321-2329

10. Werler MM, Mitchell AA, Hernandez-Diaz S, Honein MA: Use of over-the-counter medications during pregnancy. Am J Obstet Gynecol 2005, 193:771-777

11. Black RA, Hill DA: Over-the-counter medications in pregnancy. Am Fam Physician 2003, 67:2517-2524

12. Etminan M, Sadatsafavi M, Jafari S, Doyle-Waters M, Aminzadeh K, FitzGerald JM: Acetaminophen use and the risk of asthma in children and adults: a systematic review and metaanalysis. Chest 2009, 136: $1316-1323$

13. Eyers $S$, Weatherall M, Jefferies S, Beasley R: Paracetamol in pregnancy and the risk of wheezing in offspring: a systematic review and meta-analysis. Clin Exp Allergy 2011, 41:482-489

14. Kämmerer U, Eggert AO, Kapp M, McLellan AD, Geijtenbeek TBH, Dietl J, van Kooyk Y, Kämpgen E: Unique appearance of proliferating antigen-presenting cells expressing DC-SIGN (CD209) in the decidua of early human pregnancy. Am J Pathol 2003, 162:887-896
15. Blois S, Tometten M, Kandil J, Hagen E, Klapp BF, Margni RA, Arck PC: Intercellular adhesion molecule-1/LFA-1 cross talk is a proximate mediator capable of disrupting immune integration and tolerance mechanism at the feto-maternal interface in murine pregnancies. J Immunol 2005, 174:1820-1829

16. Miwa N, Hayakawa S, Miyazaki S, Myojo S, Sasaki Y, Sakai M, Takikawa O, Saito S: IDO expression on decidual and peripheral blood dendritic cells and monocytes/macrophages after treatment with CTLA-4 or interferon- $\gamma$ increase in normal pregnancy but decrease in spontaneous abortion. Mol Hum Reprod 2005, 11:865-870

17. Sasaki Y, Sakai M, Miyazaki S, Higuma S, Shiozaki A, Saito S: Decidual and peripheral blood $\mathrm{CD} 4+\mathrm{CD} 25+$ regulatory $\mathrm{T}$ cells in early pregnancy subjects and spontaneous abortion cases. Mol Hum Reprod 2004, 10:347-353

18. Samstein RM, Josefowicz SZ, Arvey A, Treuting PM, Rudensky AY: Extrathymic generation of regulatory $\mathrm{T}$ cells in placental mammals mitigates maternal-fetal conflict. Cell 2012, 150:29-38

19. Blois SM, Joachim R, Kandil J, Margni R, Tometten M, Klapp BF, Arck PC: Depletion of CD8+ cells abolishes the pregnancy protective effect of progesterone substitution with dydrogesterone in mice by altering the Th1/Th2 cytokine profile. J Immunol 2004, 172:5893-5899

20. Tilburgs T, Schonkeren D, Eikmans M, Nagtzaam NM, Datema G, Swings GM, Prins F, van Lith JM, van der Mast BJ, Roelen DL, Scherjon SA, Claas FH: Human decidual tissue contains differentiated $\mathrm{CD} 8+$ effector-memory $\mathrm{T}$ cells with unique properties. $\mathrm{J}$ Immunol 2010, 185:4470-4477

21. Riella LV, Dada S, Chabtini L, Smith B, Huang L, Dakle P, Mfarrej B, D'Addio F, Adams L-T, Kochupurakkal N, Vergani A, Fiorina P, Mellor AL, Sharpe AH, Yagita H, Guleria I: B7h (ICOS-L) maintains tolerance at the fetomaternal interface. Am J Pathol 2013, 182:2204-2213

22. Solano ME, Kowal MK, O'Rourke GE, Horst AK, Modest K, Plösch T, Barikbin R, Remus CC, Berger RG, Jago C, Ho H, Sass G, Parker VJ, Lydon JP, DeMayo FJ, Hecher K, Karimi K, Arck PC: Progesterone and HMOX-1 promote fetal growth by CD8 $+\mathrm{T}$ cell modulation. J Clin Invest 2015, 125:1726-1738

23. Levy G, Garrettson LK, Soda DM: Evidence of placental transfer of acetaminophen. Pediatrics 1975, 55:895

24. Byer A, Traylor T, Semmer J: Acetaminophen overdose in the third trimester of pregnancy. JAMA 1982, 247:3114-3115

25. Khurana S, Mukhopadhyay A: Hematopoietic progenitors from early murine fetal liver possess hepatic differentiation potential. Am J Pathol 2008, 173:1818-1827

26. Solano ME, Jago C, Pincus MK, Arck PC: Highway to health; or how prenatal factors determine disease risks in the later life of the offspring. J Reprod Immunol 2011, 90:3-8

27. Kalkunte S, Boij R, Norris W, Friedman J, Lai Z, Kurtis J, Lim K-H, Padbury JF, Matthiesen L, Sharma S: Sera from preeclampsia patients elicit symptoms of human disease in mice and provide a basis for an in vitro predictive assay. Am J Pathol 2010, 177:2387-2398

28. Gonzalez JM, Franzke CW, Yang F, Romero R, Girardi G: Complement activation triggers metalloproteinases release inducing cervical remodeling and preterm birth in mice. Am J Pathol 2011, 179: $838-849$

29. Wan YY, Flavell RA: Identifying Foxp3-expressing suppressor $\mathrm{T}$ cells with a bicistronic reporter. Proc Natl Acad Sci U S A 2005, 102 : $5126-5131$

30. Kamanaka M, Kim ST, Wan YY, Sutterwala FS, Lara-Tejero M, Galán JE, Harhaj E, Flavell RA: Expression of interleukin-10 in intestinal lymphocytes detected by an interleukin-10 reporter knockin tiger mouse. Immunity 2006, 25:941-952

31. Mannery YO, Ziegler TR, Park Y, Jones DP: Acetaminophen elimination half-life in humans is unaffected by short-term consumption of sulfur amino acid-free diet. J Pharmacol Exp Ther 2010, 333:948-953

32. Sonawane B, Sills M, Schrager R, Yaffe S: 371 Acute starvation and acetaminophen toxicity in young vs adult mice. Pediatr Res 1981, 15: 502 
33. Barikbin R, Neureiter D, Wirth J, Erhardt A, Schwinge D, Kluwe J, Schramm C, Tiegs G, Sass G: Induction of heme oxygenase 1 prevents progression of liver fibrosis in Mdr2 knockout mice. Hepatology 2012, 55:553-562

34. Arck PC, Hecher K, Solano ME: B cells in pregnancy: functional promiscuity or tailored function? Biol Reprod 2015, 92:12

35. Zhang CC, Lodish HF: Insulin-like growth factor 2 expressed in a novel fetal liver cell population is a growth factor for hematopoietic stem cells. Blood 2004, 103:2513-2521

36. Larrey D, Letteron P, Foliot A, Descatoire V, Degott C, Geneve J, Tinel M, Pessayre D: Effects of pregnancy on the toxicity and metabolism of acetaminophen in mice. J Pharmacol Exp Ther 1986, 237:283-291

37. Mcelhatton PR, Sullivan FM, Volans GN: Paracetamol overdose in pregnancy analysis of the outcomes of 300 cases referred to the teratology information service. Reprod Toxicol 1997, 11:85-94

38. Karimi K, Keßler T, Thiele K, Ramisch K, Erhardt A, Huebener P, Barikbin R, Arck P, Tiegs G: Prenatal acetaminophen induces liver toxicity in dams, reduces fetal liver stem cells, and increases airway inflammation in adult offspring. J Hepatol 2015, 62:1085-1091

39. Rayburn W, Shukla U, Stetson P, Piehl E: Acetaminophen pharmacokinetics: comparison between pregnant and nonpregnant women. Am J Obstet Gynecol 1986, 155:1353-1356

40. Roberts D, Bucci T, Benson R, Warbritton A, McRae T, Pumford N, Hinson J: Immunohistochemical localization and quantification of the 3-(cystein-S-yl)-acetaminophen protein adduct in acetaminophen hepatotoxicity. Am J Pathol 1991, 138:359-371

41. Patel R, Rosengren RJ: Acetaminophen elicits anti-estrogenic but not estrogenic responses in the immature mouse. Toxicol Lett 2001, 122 : 89-96

42. Lockwood CJ, Kayisli UA, Stocco C, Murk W, Vatandaslar E, Buchwalder LF, Schatz F: Abruption-induced preterm delivery is associated with thrombin-mediated functional progesterone withdrawal in decidual cells. Am J Pathol 2012, 181:2138-2148

43. Jaeschke $\mathrm{H}$ : Role of inflammation in the mechanism of acetaminophen-induced hepatotoxicity. Expert Opin Drug Metab Toxicol 2005, 1:389-397

44. Care AS, Diener KR, Jasper MJ, Brown HM, Ingman WV, Robertson SA: Macrophages regulate corpus luteum development during embryo implantation in mice. J Clin Invest 2013, 123:3472-3487

45. Blois SM, Ilarregui JM, Tometten M, Garcia M, Orsal AS, CordoRusso R, Toscano MA, Bianco GA, Kobelt P, Handjiski B, Tirado I, Markert UR, Klapp BF, Poirier F, Szekeres-Bartho J, Rabinovich GA, Arck PC: A pivotal role for galectin-1 in fetomaternal tolerance. Nat Med 2007, 13:1450-1457
46. Chaudhry A, Rudensky AY: Control of inflammation by integration of environmental cues by regulatory T cells. J Clin Invest 2013, 123 : 939-944

47. Poojary KV, Kong YM, Farrar MA: Control of Th2-mediated inflammation by regulatory T cells. Am J Pathol 2010, 177: $525-531$

48. Dobaczewski M, Xia Y, Bujak M, Gonzalez-Quesada C, Frangogiannis NG: CCR5 signaling suppresses inflammation and reduces adverse remodeling of the infarcted heart, mediating recruitment of regulatory T cells. Am J Pathol 2010, 176:2177-2187

49. Hartwig IRV, Pincus MK, Diemert A, Hecher K, Arck PC: Sexspecific effect of first-trimester maternal progesterone on birthweight. Hum Reprod 2013, 28:77-86

50. Rollins DE, von Bahr C, Glaumann H, Moldeus P, Rane A: Acetaminophen: potentially toxic metabolite formed by human fetal and adult liver microsomes and isolated fetal liver cells. Science 1979, 205:1414-1416

51. Naito M, Takahashi K, Nishikawa S: Development, differentiation, and maturation of macrophages in the fetal mouse liver. J Leukoc Biol 1990, 48:27-37

52. Dzierzak E, Medvinsky A, de Bruijn M: Qualitative and quantitative aspects of haematopoietic cell development in the mammalian embryo. Immunol Today 1998, 19:228-236

53. Henderson AJ, Shaheen SO: Acetaminophen and asthma. Paediatr Respir Rev 2013, 14:9-16

54. Beyer RP, Fry RC, Lasarev MR, McConnachie LA, Meira LB, Palmer VS, Powell CL, Ross PK, Bammler TK, Bradford BU, Cranson AB, Cunningham ML, Fannin RD, Higgins GM, Hurban P, Kayton RJ, Kerr KF, Kosyk O, Lobenhofer EK, Sieber SO, Vliet PA, Weis BK, Wolfinger R, Woods CG, Freedman JH, Linney E, Kaufmann WK, Kavanagh TJ, Paules RS, Rusyn I, Samson LD, Spencer PS, Suk W, Tennant RJ, Zarbl H: Multicenter study of acetaminophen hepatotoxicity reveals the importance of biological endpoints in genomic analyses. Toxicol Sci 2007, 99: 326-337

55. Harrill AH, Ross PK, Gatti DM, Threadgill DW, Rusyn I: Populationbased discovery of toxicogenomics biomarkers for hepatotoxicity using a laboratory strain diversity panel. Toxicol Sci 2009, 110: 235-243

56. Court MH, Peter I, Hazarika S, Vasiadi M, Greenblatt DJ, Lee WM; Acute Liver Failure Study Group: Candidate gene polymorphisms in patients with acetaminophen-induced acute liver failure. Drug Metab Dispos 2014, 42:28-32

57. Edwards MJ: Review: hyperthermia and fever during pregnancy. Birth Defects Res Part A Clin Mol Teratol 2006, 76:507-516 